\title{
Prevalence and factors influencing behavioral problems among adolescents in selected high schools of Bhubaneswar: A survey in Odisha
}

Eliza $\mathrm{R}^{1 *}$, Jayakrishnan $\mathrm{K}^{2}$

*Corresponding author:

${ }^{1}$ Ms Eliza Rath, MSc Nursing, Prativa Devi College of Nursing, Bhubaneswar, Odisha

Email: eliza.rath1@gmail.com, $\underline{\text { ORCID }}$

${ }^{2}$ All India Institute of Medical Sciences, Patna, Bihar, India

Information about the article:

Received: Jan. 17, 2019

Accepted: Feb. 20, 2019

Published online: Dec. 27, 2019

\section{Publisher}

Nepal Health Research Society, Bahundhara -6, Gokarnesowor Municipality, Kathmandu, Nepal

eISSN 2382-5545, ISSN 2676-1343 (Print)

(C) The Author(s). 2019

Content licensing: CC BY 4.0

\begin{abstract}
Background

Adolescent health and well-being are important for the health of future generation. Adolescence is a period of complex amalgamation of emotional, physical and social development leading to functional independence of the individual. It is also a period when behavioral problems could adversely impact the mental health. Timely identification and utilization of support system could lead better adjustment and less emotional and behavioral problems in adolescents. The objective of the present study was to identify the prevalence and the factors influencing behavioral problems among adolescents.
\end{abstract}

\section{Materials and methods}

Behavioral problems such as depression, substance abuse, suicidal tendency and conduct disorder were surveyed in schools. A total of 300 adolescents (150 boys and 150 girls) responded to the survey questions. Beck's depression inventory, adolescent alcohol and drug involvement scale, suicidal behavioral questionnaire revised were used to examine depression, substance abuse and suicidal tendency respectively. Self structured questionnaire were used to evaluate conduct disorder and the factors influencing behavioral problems. The self designed tools were validated by seven multi disciplinary experts from pediatric, nursing, psychology and psychiatrics.

\section{Results}

Prevalence of various conditions is reported, depression was reported by $36 \%$, drug abuse is $16 \%$, conduct disorder was observed in $45 \%$ and $27 \%$ risk of suicide. Age, class and gender have a strong association with behavioral problems. In this study it has shown that females are more affected by behavioral problems than males and more problems are reported in higher class's students. Attitude of mother has a strong impact on behavior of an adolescent. Overall, the current study highlights the prevalence and the factors that impact behavioral conditions in adolescents.

\section{Conclusion}

It concludes that behavioral problems among adolescents are common. They are often under recognized. Identification and recognition through proper assessment is needed to give them right referral.

\section{Keywords}

Adolescents, behavioral problems, conduct disorder, depression, substance abuse 